\title{
Article
}

\section{The effect of aggression management training programmes for nursing staff and students working in an acute hospital setting. A narrative review of current literature}

Heckemann, B., Zeller, A., Hahn, S., Dassen, T., Schols, J.M.G.A. and Halfens, R.J.G.

Available at http://clok.uclan.ac.uk/13607/

Heckemann, B., Zeller, A., Hahn, S. ORCID: 0000-0002-2697-2014, Dassen, T., Schols, J.M.G.A. and Halfens, R.J.G. (2014) The effect of aggression management training programmes for nursing staff and students working in an acute hospital setting. A narrative review of current literature. Nurse Education Today, 35 (1). pp. 212-219. ISSN 0260-6917

It is advisable to refer to the publisher's version if you intend to cite from the work. http://dx.doi.org/10.1016/j.nedt.2014.08.003

For more information about UCLan's research in this area go to http://www.uclan.ac.uk/researchgroups/ and search for <name of research Group>.

For information about Research generally at UCLan please go to http://www.uclan.ac.uk/research/

All outputs in CLoK are protected by Intellectual Property Rights law, including Copyright law. Copyright, IPR and Moral Rights for the works on this site are retained by the individual authors and/or other copyright owners. Terms and conditions for use of this material are defined in the policies page.

\section{CLoK}

Central Lancashire online Knowledge www.clok.uclan.ac.uk

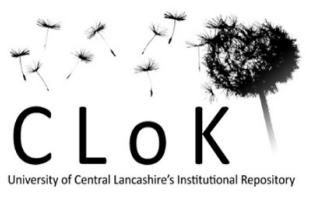


Full title

The participant's perspective: Learning from an aggression management training course for nurses. Insights from a qualitative interview study.

\begin{tabular}{|c|c|c|c|c|c|}
\hline \multirow[t]{2}{*}{ Author's details } & \multicolumn{5}{|c|}{ Author contributions } \\
\hline & $\begin{array}{l}\text { Study } \\
\text { conception/ } \\
\text { design }\end{array}$ & $\begin{array}{l}\text { Data } \\
\text { collection/ } \\
\text { analysis }\end{array}$ & $\begin{array}{l}\text { Drafting of } \\
\text { manuscript }\end{array}$ & $\begin{array}{l}\text { Critical } \\
\text { revisions of } \\
\text { intellectual } \\
\text { content }\end{array}$ & $\begin{array}{l}\text { Super- } \\
\text { vision }\end{array}$ \\
\hline $\begin{array}{l}\text { Birgit HECKEMANN }^{1} \\
\text { RN, MSc, PhD candidate }\end{array}$ & & & & & \\
\hline $\begin{array}{l}\text { Helga Elisabeth BREIMAIER }{ }^{2} \\
\text { RN, MScN, PhD Candidate, Academic } \\
\text { Teacher, Junior Researcher }\end{array}$ & & & & & \\
\hline $\begin{array}{l}\text { Ruud J.G. HALFENS }{ }^{1} \\
\text { PhD. FEANS, Associate Professor in } \\
\text { Nursing Science } \\
\text { Department of Health Services Research }\end{array}$ & & & & & \\
\hline $\begin{array}{l}\text { Jos M.G.A. SCHOLS }{ }^{1} \\
\text { MD, PhD. Professor of Old Age } \\
\text { Medicine Department of Family } \\
\text { Medicine and Department of Health } \\
\text { Services Research }\end{array}$ & & & & & \\
\hline $\begin{array}{l}\text { Sabine HAHN } \\
\text { MNS, PhD } \\
\text { Head of Nursing Discipline, Division } \\
\text { Head of Applied Research \& } \\
\text { Development in Nursing }\end{array}$ & & & & & \\
\hline \multicolumn{6}{|c|}{$\begin{array}{l}\text { Affiliations } \\
\text { 1. Caphri - School for Public Health and Primary Care } \\
\text { Maastricht University, Maastricht, the Netherlands } \\
\text { 2. Institute of Nursing Science } \\
\text { Medical University of Graz, Graz, Austria } \\
\text { 3. Bern University of Applied Sciences, Bern, Switzerland }\end{array}$} \\
\hline
\end{tabular}

Acknowledgements: We are very grateful to the nurses who participated in this study for sharing their experiences, learning and their time so generously.

Ethical approval: Two responsible cantonal Swiss ethics committees reviewed the study plan and decided that a formal application was not necessary.

\section{Conflict of interest: None.}

Funding: This research received no specific grant from any funding agency in the public, commercial or non-profit sectors.

\section{ABSTRACT}

Background: Aggression management training for nurses is an important part of a comprehensive strategy to reduce patient and visitor aggression in healthcare.

Although training is commonplace, few scientific studies examine its benefits. 
Aim: To explore and describe, from a nurse's perspective, the learning gained from attending aggression management training

Design and methods: This was a descriptive qualitative interview study. We conducted semi-structured individual interviews with seven nurses before (September/October 2012) and after they attended aggression management training (January/February 2013). Interview transcripts were content-analysed qualitatively.

Ethical issues: The study plan was reviewed by the responsible ethics committees. Participants gave written informed consent.

Findings: Aggression management training did not change nurses' attitude. Coping emotionally with the management of patient and visitor aggression remained a challenge. Nurses' theoretical knowledge increased, but they did not necessarily acquire new strategies for managing patient/visitor aggression. Instead, the course refreshed or activated existing knowledge of prevention, intervention and deescalation strategies. Nurses' situational awareness for early signs of patient and visitor aggression, environmental and emotional skills awareness increased. Nurses became more confident in dealing with hazardous situations. While the training influenced nurses' individual clinical practice, learning was rarely shared within teams.

Conclusions: Aggression management training increases skills, knowledge and confidence in dealing with patient or visitor aggression, but the emotional management remains a challenge. Future research should investigate how aggression management training courses can strengthen nurses' ability to emotionally cope with patient and visitor aggression. More knowledge is needed on how the theoretical and practical knowledge gained from the training may be disseminated more effectively within teams and thus contribute to the creation of low-conflict ward cultures.

\section{Keywords}

Training; aggression management; nurses; qualitative research; qualitative descriptive content analysis; learning; aggression, healthcare 


\section{INTRODUCTION AND BACKGROUND}

Aggression in healthcare settings is a complex problem with serious negative consequences. Aggression may be expressed verbally (e.g. threats, harassment, bullying, verbal abuse), or physically (e.g. slapping, kicking, biting, stabbing) $(1,2)$. Perpetrators may be co-workers, managers, patients or visitors (3). The majority of acts of physical or verbal aggression originate from patients or visitors (4-9). While most incidents of patient or visitor aggression (PVA) arise in mental health and accident and emergency departments $(10,11)$, PVA also occurs in other clinical settings, such as medical and surgical departments $(12,13)$. Frequent staff exposure to aggression hampers recruitment and retention, and engenders a multitude of problems in the workforce, such as heightened risk of burnout, sleep disturbance, anxiety, as well as intent to leave the profession $(6,9,14,15)$. PVA is influenced by a variety of internal, external and interactional factors (16) and there is to date no comprehensive theory of PVA and how it emerges in the inpatient setting (17). The development, application and evaluation of a theory that amalgamates current scientific knowledge will be a crucial to step towards better management of PVA in clinical practice.

Initiating and maintaining a nurse-patient relationship that is underpinned by an attitude of positive evaluation, equality, patient participation and autonomy may prevent PVA (18-21). Yet inpatient care is often delivered in fast-paced environments with rapid turnover, which allow little time for establishing caring relationships. Moreover, the necessity to penetrate patients' physical privacy during nursing interventions may induce feelings of fear or threat. These can trigger aggressive patient responses (22). Aggressive episodes develop over five phases (trigger, escalation, crisis, plateau and post crisis depression phase) (23). Detecting aggression, intervening and de-escalating at an early stage are essential (24). Regular aggression management (AM) training aims to increase staff knowledge and foster interactional competencies, such as preventing and de-escalating PVA verbally and non-verbally in a non-coercive, collaborative, and interactional approach (25). AM training also aims to modify nurses' attitudes towards PVA, as attitudes influence the management of PVA (26). Nurses' attitudes have been examined from a number of vantage points (11): their experience and prediction of aggression (27), attitudes towards physical assault (28), or causal factors and management of aggression (29). In clinical practice, nurses are perpetually challenged to cope with the emotional impact of PVA $(6,9)$. The importance of strengthening the ability to manage demanding situations has only recently been acknowledged. Fostering coping skills and resilience are now recommended components of AM training $(30,31)$. Although there is ample guidance for designing AM training, scientific evidence proving its actual benefits is limited (32): a number of literature reviews synthesizing evidence on the effect of AM training point to predominantly low quality of research (33-37). In practice, AM training evaluation has been criticized for failing to go beyond "happy sheets", i.e., feedback forms filled in by course participants on completion of the training $(25,32)$. Such feedback forms tend to elicit the course participants' immediate satisfaction with the training, the aspects they liked and disliked (38). In-depth evaluation is crucial to determine if AM training meets the stated objectives and is appropriate for the target 
group, as well as to ensure appropriate allocation of financial resources for costly training courses (32).

\section{THE STUDY}

\section{Aims}

The aim of this study was to obtain insight, from a nurses' perspective, into learning gained from attending AM training

1: How does AM training affect nurses' attitude towards and coping with PVA?

2: How does AM training influence nurses' PVA prevention, early intervention and de-escalation strategies?

\section{Design}

We conducted semi-structured qualitative interviews before and after an AM training for registered nurses working in Swiss hospitals. The interviews were content analysed (39). Emerging themes were compared to establish the influence of AM training on nurses' attitudes towards and ability to cope with, prevent, and manage PVA.

Description of the aggression management training programs

Nurses participated in either AM training 'A' or 'B'. Both programs were developed at Swiss universities of applied sciences and delivered in October and November 2012 ('A'), or from October until December 2012 ('B').

Trainings ' $A$ ' and ' $\mathrm{B}$ ' were similar in content, teaching methods and input time. The main difference was that training ' $\mathrm{B}$ ', being part of a degree pathway, featured more theoretical input on legal and institutional aspects. Table 1 provides details of both training programs. Nurse education in Switzerland has undergone substantial reform over the past two decades. Today, diploma level nursing is taught at bachelor's degree level across five Swiss universities of applied sciences. Prior to reform, nurses obtained a diploma by training in schools of nursing which were linked to hospitals. Program 'B' participants had qualified before the transition to tertiary nurse education was completed. They were working clinically and studying part-time towards a Bachelor of Science (BSc) degree.

Table 1: Details of aggression management training 'A and 'B'

INSERT TABLE 1 here

\section{Sample}

Registered nurses qualified at diploma level and participating in either AM training ' $A$ ' or 'B' were eligible for inclusion. Participants were recruited from a population of 28 eligible nurses. Course attendants received an invitation and information letter via the respective institutions organising the course. They were invited to reply directly to the researcher. This approach ensured that course leaders remained unaware of who participated, and limited the researcher's access to contact details to those of study volunteers. The invitation and information letter outlined the study's objectives and 
the main researcher's professional background. A total of nine nurses replied to the invitation. One respondent declined to participate due to lack of time, and one respondent was unreachable after initial email exchange. The final sample consisted of seven nurses who participated in two interviews each: one interview before and one after the AM training.

Data collection and analysis

Interviews were conducted in September/October 2012 (1-4 weeks before AM training) and between January/February 2013 (3-12 weeks after AM training) by BH in German. BH prepared for the task by interview simulation. Interview guides were modified from Naish et al. (40) (written permission obtained). Naish et al. (2002) identified key issues in aggression within a primary health care and community setting. Naish et al.'s (2002) guide was translated into German and adapted to the study's purposes by consensus of a team of healthcare researchers including two experts on aggression management. We developed a guide for the interviews before the training and one for interviews after the training. Table 2 shows section headings and example questions for both guides. The guides were pilot-tested on two volunteer healthcare professionals. Testing revealed that no further changes were necessary.

Table 2: Interview guides before and after the AM training. Section headings and example questions

\section{INSERT TABLE 2 HERE}

The study participants chose the mode of interview: face-to-face, Skype ${ }^{\mathrm{TM}}$ videotelephony (Microsoft Corp., Redmond, Washington, USA), or telephone. Face-to-face interviews were conducted in a quiet meeting room on the hospital premises.

Telephone or Skype interviews took place at the participants' choice of location. Table 3 (below) shows participants' choice of interview mode and duration.

Table 3: Participants' choice of interview mode and interview duration INSERT TABLE 3 HERE

All interviews were digitally recorded and transcribed by $\mathrm{BH}$. $\mathrm{BH}$ coded both before and after AM training interviews. The base unit of analysis was the sentence. Sentences in a sequence logically pertaining to particular ideas or thoughts were coded as a single unit. An initial round of deductive (template) coding (41) and content memo writing was followed by inductive coding. In a third cycle, we reviewed and condensed the coding. HEB and $\mathrm{BH}$ reviewed the resulting coding frame and memos, resolved differences through discussion (42) and collaboratively interpreted the data (43). The initial interviews provided a baseline, i.e. a description of the situation before the AM training for comparison with the results of the interviews after the AM training. We created an audit trail of the code lists from the different stages of the coding process in MAXQDA $\AA$, a software for computerassisted qualitative data analysis (VERBI GmbH, Berlin, Germany).

Figure 1 illustrates the coding process. 


\section{INSERT FIGURE 1 HERE}

Figure 1: The coding process

Figure 2 and 3 show the final coding templates before (Figure 2) and after the training (Figure 3).

\section{INSERT FIGURE 2 HERE}

Figure 2: The final model of analysis: the initial situation baseline (interviews before aggression management training)

\section{INSERT FIGURE 3 HERE}

Figure 3: Final model of analysis: the follow-up (interviews after aggression management training)

\section{Ethical considerations}

The two responsible Swiss cantonal ethics committees reviewed the study plan and decided that a formal application was not necessary.

The respective organizers of the training (one hospital - training ' $A$ ' and one university of applied sciences - training ' $\mathrm{B}$ ') gave permission for the study in writing.

All study participants gave written informed consent. They were advised that participation was voluntary and that they could withdraw from the study at any point. All personally identifiable information was coded in the interview transcripts.

\section{Validity and rigour}

Credibility, authenticity, criticality and integrity are primary criteria of validity in qualitative research(44). We strengthened the credibility and authenticity, i.e. the study's interpretive and descriptive quality (44) by interpreting the interviews at a fairly superficial level: we treated language as "a vehicle of communication, not itself an interpretive structure" (45). By remaining closer to the data than researchers with other methodological orientations (e.g. phenomenology or grounded theory), we increase the transparency of our interpretations for our readers (45). We addressed the criterion of criticality (44) by creating an auditable trail comprising the raw interview data, coding records and handwritten notes (46). The handwritten notes also strengthen our study's integrity, as they are a track record of our discussions and thoughts during the interpretation process (44).

\section{FINDINGS}

Four participants were female, three male. Two had between 1-5 years, four between 6-10 and one more than 10 years of clinical nursing experience. They encountered varying degrees of PVA within their clinical areas. Four nurses who worked on mixed speciality or medical wards rarely (i.e. less than once a week) experienced PVA either as verbal aggression (snubbing of staff, rudeness) or physical attacks mainly originating from confused patients or patients suffering from dementia. Three nurses 
employed in intensive care, an emergency department, or heroin-assisted treatment experienced verbal or physical PVA frequently (i.e. several times a week to daily).

Four categories described the effect of AM training: (1) learning effect, (2) translation of learning into clinical practice, (3) attitudes towards patients' behaviour and (4) coping and self-management of emotions.

The categories are described in more depth in the following section.

Category 1: Learning effect

Nurses gained knowledge on theories of aggression, influencing interactional factors (e.g. body language, physical proximity), situational and environmental factors (e.g. architectural features and lighting). Some nurses became aware of the subjectivity of aggression and the complexity and multifactorial nature of PVA. Interestingly, the nurses did not necessarily acquire new PVA management strategies. Instead, the training refreshed existing knowledge, or nurses recognised that they had previously been using de-escalation strategies intuitively. Practical exercises such as a role-play deepened the learning experience as nurses practiced de-escalation and aggression management skills in a safe but realistic setting. Overall, the training increased nurses' confidence in dealing with aggressive situations, particularly in those participants who had been less experienced in dealing with PVA. Participants also became more aware of their own limitations. Particularly nurses who were frequently exposed to aggression appreciated that not all situations can be controlled or completely de-escalated:

Nurse 7: "[...] most of the times my goal [...] is stop the aggression and to try to pull someone out of their aggressive behaviour. The training showed me quite plainly that this is sometimes [...] too high a goal, which is simply not achievable. [...] In such [very difficult] situations the goal may well be to prevent physical violence."

\section{Category 2: Translation of learning into clinical practice}

The learning affected participants' prevention, early intervention and de-escalation of PVA. However, they rarely shared their learning with their colleagues.

Prevention

Before attending AM training:

Nurses highlighted the importance of preventing PVA by approaching patients in a respectful manner. They strove to avoid conflict by taking the patient seriously and being responsive, i.e. communicating with the patient and finding consensus. Nurses tried to be flexible and accommodate patients' wishes to prevent conflict situations.

After the AM training:

Nurses' retained their prevention strategies in essence, but developed some refinement. They strove, for example, to keep patients informed during waiting periods and reported paying increased attention to maintaining an appropriate physical distance as well as to their tone of voice, gestures, body posture and positioning in their interactions with patients or visitors. They were also more mindful of facial patient cues or gestures and, as a result, noticed and appropriately addressed situations with potential for aggression earlier. 
Early intervention and de-escalation

Before the AM training :

Most nurses described how they managed early stages of the assault cycle by communicating and showing empathy. If this strategy failed, most nurses left a situation before it became confrontational:

Nurse 6: "I crave harmony very, very much [...] I start to make concessions, I try to come to a compromise, I try to achieve a lot through talking, particularly with aggressive patients, [...] [sometimes] I might send in a colleague or maybe the physician [...]."

One nurse described a more proactive approach:

Nurse 7: “ [...] You notice these tiny little signals [...] that indicate the beginnings of aggression and that require immediate intervention on our behalf. [...] [My strategy] depends on the patient. [...] if I do not know someone at all, I would probably say:

"Oh, you are frightening me, you look as if you could crawl up the walls and destroy our furniture". [...]. And then, very often, there is a deep breath and, then the reply: "yes, you are right". And then, violence is almost not possible any more."

After the AM training:

Nurses employed the de-escalation strategies more consciously as their actions were now underpinned by theoretical knowledge:

Nurse 2: "[The training] showed me some strategies, clarified the gos and no-gos [...]. These were actually not [new strategies]. But there are some things that you have to [...] hear a hundred times [...], so they remain somewhat present and you [...] internalize [them]."

Some nurses highlighted the importance of using strategies in a genuine and authentic fashion, rather than playacting them. Nurses felt they had more options to choose how to respond to aggressive behaviour. They also became more discerning about using sedation and restraint in response to patient aggression:

Nurse 6: " [I learned] that in some situations, you definitely can't avoid sedation or restraint, but in very, very many [situations] these [measures] can have the opposite effect and you don't have to restrain people just to spare the team. [...]"

\section{Category 3: Attitude towards patient's behaviour}

'Attitude towards PVA' in this study was defined as 'nurses' favourable or unfavourable evaluation of patient responsibility for PVA' (46), i.e. the extent to which nurses held patients accountable or attributed blame for their aggressive behaviour. The attitude determined nurses' emotional response to PVA. If underlying factors such as an illness or side effects of medication caused the PVA, nurses did not attribute blame and tended to remain emotionally detached. Nurses attributed blame if 
behaviour was perceived as a disproportionate reaction, as disrespectful or offensive. This triggered emotional responses in nurses. The majority of nurses reacted by withdrawing and minimising personal contact to avoid further conflict. Only one nurse emphasized the importance of sustaining a dialogue in those situations.

Nurse 1: [...] In those situations where you know exactly why this person is confused and why he is aggressive I succeed, I believe, to dissociate [myself from taking PVA personally] relatively well, but this is more difficult if, for example, someone, because he has to wait for his meal or so, becomes very aggressive and [this behaviour] is, from my point of view, exaggerated.

Nurses' attitude towards PVA did not change after AM training. In the interviews following the intervention, one nurse illustrated vividly how behaviour that she perceived as disrespectful challenged her, as in her role as a nurse, she was expected to show respect towards patients at all times:

Nurse 4: " [...] [the AM training] was at a good point in time. [...] Because I had been in this situation where this patient insulted me as a German nurse, and this hurt me quite a bit. I was thinking [...] "I DON'T have to put up with this" [...] why do I always have to understand everything? Only because I am a nurse, [patients] cannot treat me however way they want. [...] But then, you always have to look at these trigger factors and such [...]. I often think [...] hey, I have to pull myself together, [...] the patient could also pull himself together. [...] I still find this difficult. Because, in this training, it is being conveyed that [...] the patient cannot help but be aggressive, whereas I think: Sure! [...] I have been brought up to show another person respect, why then, does [the patient] not do this?"

\section{Category 4: Coping}

Coping has been defined as 'the process of managing demands (external or internal) that are appraised as taxing or exceeding the resources of the person' (47). This study focused on how nurses managed their own emotions evoked by aggressive situations.

Before the AM training:

Nurses highlighted that staying calm and controlling one's own emotions when facing PVA were hallmarks of professionalism, but they also talked about how upsetting, anger- or fear-inducing the experience of PVA could be. When nurses themselves became angry, they tried to calm themselves down by justifying, explaining or trying to understand the patient's situation. If they were too upset, they had to remove themselves from the situation. Team colleagues were an important resource for coping with these emotions:

Nurse 2: "[...] you just go into the room where we prepare the medications and drag someone in with you and quickly let off steam. [...]. [Maintaining] mental hygiene is actually important. To outsiders, this sounds very judgmental, very derogatory, very devaluing, yeah? And, you have to tell yourself, "good, I need this now" and then you can go in [to the patient's room again] [pause] and it is ok again." 
Nurse 5: "Well, we talk about the patient and such. You have to, how do you say, get rid of your aggression somehow and crack some jokes about the patient and such. I mean, we work a lot with humour. It is actually not good if someone else hears this, but well, we get rid of a lot [through humour], we laugh a lot during the breaks [...]."

Mutual social support from colleagues was important in aggressive situations (i.e. coming to each other's aid), and for provision of aftercare:

Nurse 7: "[...] the communication with my colleagues [is important], to confirm with each other that how we acted was ok, that [we took] the right decision. But also to reflect on, where there would have been points where we could have acted even better."

After the training :

The interviews after AM training showed that emotional self-management of PVA had not changed to a large degree. Team and individual colleagues remained as important a resource for coping with PVA, but some nurses also talked about having obtained new personal strategies to cope with their own emotions by creating some space between themselves and the aggressive situation. Some participants explained how they were better able to let go of their emotions and better able to choose how to respond to the patient:

Nurse 4:" [...] you should find your own strategy [...]. Look out of the window, count to ten, or, well look at the clock or [do] anything that's quickly [done], that's not obvious to the other person, but that somewhat removes you from the situation, from the feeling the situation triggered in you."

The ability to manage one's own emotions appeared not to have increased substantially. Remaining emotionally dissociated remained a challenge. Perceived changes were subtle and expressed in tentative language:

Nurse 2: "Yes, [I let off steam with my colleagues] maybe a little, well, less. Maybe a little later, or so, [...] because I can be a bit more relaxed in the [aggressive] situation, because I may not be drawn into it sooooo easily. “

(below) illustrates the findings of this study.

\section{INSERT FIGURE 4 HERE}

Figure 4: Results: learning from an aggression management training course

\section{DISCUSSION}

This qualitative, longitudinal, before-and-after interview study provided insight into nurses' learning from AM training. The results show that AM training had a subtle yet tangible influence on how nurses deal with PVA. Most learning occurred at the level 
of skills and knowledge, managing the emotional impact of PVA remained challenging.

\section{Learning effect:}

The AM training mostly refreshed, activated, and extended existing strategies to manage PVA. It also increased nurses' situational, interactional and environmental awareness for PVA. These findings are in line with recent research results (48). An increase in confidence in dealing with PVA, as reported by our participants has also been shown in a number of quantitative studies (49-52). However, some nurses who were more skilled and routinely exposed to aggression in their clinical environments also realised that some situations cannot be solved or de-escalated entirely: every new situation poses a unique challenge (53). This somewhat more accepting stance towards one's own ability or even inability to solve every conflict may be related to self-compassion and better emotional coping with the effects of PVA $(54,55)$. This aspect has to date not been researched in relation to the management of PVA.

\section{Translation of learning into clinical practice:}

Our participants reported more proactive prevention and management of PVA. In essence, they were enabled to choose a more conscious and deliberate response to PVA, rather than automatically reacting to it. Our findings correspond with those of a recent mixed-methods study investigating the effect of a training session for emergency department staff (MOCA-REDI) (48). The effect of the training was assessed quantitatively in a before and after intervention staff survey, as well as qualitatively through interviews with ward managers. The qualitative MOCA-REDI interviews revealed that some staff paid more attention to preventing aggression (48). Interestingly, this observation from a ward manager view is confirmed from a staff nurse perspective in our study. However, our study does not provide an answer as to whether the training generated sustained changes. Establishing new behaviours requires time and consistency (56). Our follow-up period of 3-12 weeks may have been too short to capture such effects. Furthermore, the participants shared their learning only to a limited extent within their teams and reported no change in work routines. Teamwork is essential in creating a low-conflict ward environment (57). In order to maximize the benefit of AM training, it may be beneficial to train whole teams rather than individual staff. AM training may thus be connected to a learning approach that enables long-term capacity and competence within the whole organisation (58).

\section{Attitude towards patient behaviour}

We worked from the premise that the nurses' attitude, i.e. the positive or negative evaluation of a patient's behaviour, determines the nurse's response (47). The Attitude Towards Aggression Scale (ATAS) (27) has been developed as a tool to assess staff attitude towards aggression across five domains: (1) offensive, (2) communicative, (3)destructive, (4) protective and, (5) intrusive (27). Offensive, destructive and intrusive patient behaviour will be evaluated negatively, protective or communicative behaviour will be evaluated positively (27). Our participants described attribution of blame in line with the ATAS (27). However, an important new finding in our study is the emotional impact of negatively evaluated aggression. Patient insults, critique or rejection can be perceived as social rejection, a threat to one's own self-esteem, or perceived control (59) and trigger challenging emotions such as anger, frustration, impatience or fear. 


\section{Coping}

Although the participants acquired some strategies to help them calm down or to somewhat disengage themselves from their emotions, managing feelings of anger or fear remained a challenge. This finding affirms recent recommendations to equip staff with strategies to reduce the emotional impact of PVA $(30,31)$. The nurses identified team support as crucial in dealing with PVA. They often vented their feelings to a colleague or discussed issues within the team. Teamwork has been highlighted as essential role in creating supportive, low-conflict ward environments.

\section{Limitations}

A number of limitations apply to this study. The sampling strategy entails response bias, as those nurses who participated may have been more interested in the topic of PVA than those who declined. The number of 7 participants is small, but we achieve strong face validity thanks to the longitudinal design, where each after-training data point can be compared to a tightly corresponding baseline data point. The question how large or small a sample should be is surrounded by controversy. Our sample size is commensurate to the available resources, research questions, and design to determine the sample size (60), and we believe that the basis of our findings is solid in this respect. The scope of the study was narrow, but the sample was varied. It comprised male and female nurses from different clinical backgrounds with a range of experience of PVA. This variety added to the credibility of the results (42). Seven participants were recruited out of a population of 28 nurses. The low response rate may be ascribed to a lack of incentives to participate and that they voluntarily contributed to this study in their spare time. Considering the small sample size, we cannot claim to have reached data saturation. Further qualitative research is needed to explore if our findings can be translated or reproduced in different cultural contexts. Furthermore, the study's confirmability would have been enhanced by member checking (42).

To enable maximum flexibility, we offered our participants to choose between telephone, Skype or face-to-face interview. Although the use of a telephone and Skype video-telephony for data collection have been questioned, an empirical study demonstrated that there are no significant disadvantages of a telephone versus a faceto-face interview, on the contrary, the anonymity of a telephone conversation might add to the results (61). Likewise, a review on Skype video-telephony concludes that computer-based interviewing is not necessarily inferior to face-to-face data collection $(62)$.

\section{CONCLUSION}

AM training is an important element of an overall strategy to tackle PVA, yet to date evidence on the benefits of AM training is scarce. This study offers a unique perspective as the first qualitative interview study to investigate nurses' learning from AM training. Nurses reported increased situational and environmental awareness as well as increased confidence and improved technical skills for preventing and managing aggression. However, managing the emotional impact of PVA remained a challenge. The findings highlight the necessity for fostering skills to cope with the emotional impact of PVA as part of AM training. 


\section{REFERENCES}

1 Estryn-Behar M, van der Heijden B, Camerino D, Fry C, Le Nezet O, Conway PM, Hasselhorn, HM. Violence risks in nursing--results from the European 'NEXT' Study. Occup Med. 2008; 58: 107-14.

2 Di Martino V. Workplace violence in the health sector. 2003, Geneva: ILO/ICN/WHO/PSI.

3 Edward K, Ousey K, Warelow P, Lui S. Nursing and aggression in the workplace: a systematic review. Br J Nurs. 2014; 23: 653-9.

4 Muzembo BA, Mbutshu LH, Ngatu NR, Malonga KF, Eitoku M, Hirota R, Suganuma, N. Workplace Violence towards Congolese health care workers: a survey of 436 healthcare facilities in Katanga province, Democratic Republic of Congo. J Occup Health. 2014; 57: 69-80.

5 Swain N, Gale C, Greenwood R. Patient aggression experienced by staff in a New Zealand public hospital setting. N Z Med J. 2014; 127: 10-18.

6 Deery S, Walsh J, Guest D. Workplace aggression: the effects of harassment on job burnout and turnover intentions. Work Employ Soc. 2011; 25: 742-59.

7 Campbell J, Jill T, Kub J, Agnew J, Fitzgerald S, Fowler B, Sheridan, Daniel Lindauer C, Deaton J, Bolyard R. Workplace violence: prevalence and risk factors in the safe at work study. J Occup Environ Med. 2011; 53: 82-89.

8 Fujita S, Ito S, Seto K, Kitazawa T, Matsumoto K, Hasegawa T. Risk factors of workplace violence at hospitals in Japan. J Hosp Med. 2012; 7: 79-84.

9 Ahmed AS. Verbal and physical abuse against Jordanian nurses in the work environment. East Mediterr Health J. 2012; 18: 318-24.

10 Ferns T. Violence in the accident and emergency department--an international perspective. Accid Emerg Nurs. 2005; 13: 180-5.

11 Catlette M. A descriptive study of the perceptions of workplace violence and safety strategies of nurses working in level I trauma centers. J Emerg Nurs. 2005; 31: 519-25.

12 Hahn S, Zeller A, Needham I, Kok G, Dassen T, Halfens RJG. Patient- and visitor violence in general hospitals: a systematic review of the literature. Aggress Violent Beh. 2008; 13 431-41.

13 Winstanley S, Whittington R. Aggression towards health care staff in a UK general hospital: variation among professions and departments. J Clin Nurs. 2004; 13: 3-10.

14 Lanctôt N, Guay S. The aftermath of workplace violence among healthcare workers: a systematic literature review of the consequences. Aggress Violent Beh. 2014; 19: 492-501.

15 Jackson D, Clare J, Mannix J. Who would want to be a nurse? Violence in the workplace--a factor in recruitment and retention. J Nurs Manag. 2002; 10: 13-20.

16 Duxbury J, Whittington R. Causes and management of patient aggression and violence: staff and patient perspectives. J Adv Nurs. 2005; 50: 469-78.

17 Whittington R, Richter D. From the Individual to the Interpersonal: Environment and Interaction in the Escalation of Violence in Mental Health Settings. In: Violence in Mental Health Settings Causes, Consequences, Management (Richter D, Whittington R eds.), 2006 Springer Science + Business Media LLC, New York, USA 47 - 65. 
18 Potter SJ, McKinlay JB. From a relationship to encounter: an examination of longitudinal and lateral dimensions in the doctor-patient relationship. Soc Sci Med. 2005; 61: 465-79.

19 Hagerty BM, Patusky KL. Reconceptualizing the nurse-patient relationship. J Nurs Scholarsh. 2003; 35: 145-50.

20 Bowers L. Dangerous and Severe Personality Disorder: Response and Role of the Psychiatric Team. 2002, London, UK: Routledge.

21 Duxbury J. An evaluation of staff and patient views of and strategies employed to manage inpatient aggression and violence on one mental health unit: a pluralistic design. J Psychiatr Ment Health Nurs. 2002; 9: 325-37.

22 Winstanley S. Cognitive model of patient aggression towards health care staff: the patient's perspective. Work Stress. 2005; 19: 340 - 50.

23 Breakwell G. Coping with Aggressive Behaviour. 1997, Leicester, UK: Wiley-Blackwell.

24 Richmond JS, Berlin JS, Fishkind AB, Holloman GH, Zeller SL, Wilson MP, Rifai MA, Ng AT. Verbal de-escalation of the agitated patient: consensus statement of the American Association for Emergency Psychiatry Project BETA de-escalation workgroup. West J Emerg Med. 2012; 13:17-25.

25 Beech B, Leather P. Workplace violence in the health care sector: a review of staff training and integration of training evaluation models. Aggress Violent Beh. 2006; 11: 27-43.

26 Adler W, Kreeger P, Zeigler C. Patient violence in a private hospital. In: Assaults within Psychiatric Facilities (Lion P, Reid W eds.), 1983 Grune \& Stratton, New York, USA 81 - 9.

27 Jansen GJ, Middel B, Dassen TW. An international comparative study on the reliability and validity of the attitudes towards aggression scale. Int J Nurs Stud. 2005; 42: 467-77.

28 Collins J. Nurses' attitudes towards aggressive behaviour, following attendance at 'The Prevention and Management of Aggressive Behaviour Programme'. J Adv Nurs. 1994; 20: 117-31.

29 Duxbury J. An exploratory account of registered nurses' experience of patient aggression in both mental health and general nursing settings. J Psychiatr Ment Health Nurs. 1999; 6: 107-14.

30 Kelly EL, Subica AM, Fulginiti A, Brekke JS, Novaco RW. A cross-sectional survey of factors related to inpatient assault of staff in a forensic psychiatric hospital. J Adv Nurs. 2015; 71: 1110-22.

31 Richter D. Verbale Aggression gegen Mitarbeitende im Gesundheitswesen: Ergebnisse einer qualitativen Studie. (Verbal aggression against health-care staff: results of a qualitative study). Gesundheitswesen. 2014; 76: 494-9.

32 Zarola A, Leather P. Part 1: Research Report. In: Violence and Aggression Management Training for Trainers and Managers. A National Evaluation of the Training Provision in Healthcare Settings, 2006 Health and Safety Executive (HSE) (Crown Copyright).

33 Price 0 , Baker J, Bee P, Lovell K. Learning and performance outcomes of mental health staff training in de-escalation techniques for the management of violence and aggression. Br J Psychiatry. 2015; 206: 447-55.

34 Heckemann B, Zeller A, Hahn S, Dassen T, Schols J, Halfens R. The effect of aggression management training programmes for nursing staff and students 
working in an acute hospital setting. A narrative review of current literature. Nurs Educ Today. 2015; 35: 212-9.

35 Anderson L, FitzGerald M, Luck L. An integrative literature review of interventions to reduce violence against emergency department nurses. J Clin Nurs. 2010; 19: 2520-30.

36 Livingston JD, Verdun-Jones S, Brink J, Lussier P, Nicholls T. A narrative review of the effectiveness of aggression management training programs for psychiatric hospital staff. J Forensic Nurs. 2010; 6: 15-28.

37 Richter D, Needham I. Effekte von mitarbeiterbezogenen

Trainingsprogrammen zum Aggressionsmanagement in Einrichtungen der Psychiatrie und Behindertenhilfe - Systematische Literaturübersicht. (Effects of aggression management trainings for mental health care and disability care staff-systematic review). Psychiatr Prax. 2007; 34: 7-14.

38 Kirkpatrick D. Revisiting Kirkpatrick's four-level Model. Training \& Development. 1996; 50: 54 - 59.

39 Krippendorff K. Content Analysis: An Introduction to its Methodology. 2004, Thousand Oaks, CA: Sage Publications, Inc.

40 Naish J, Carter YH, Gray RW, Stevens T, Tissier JM, Gantley MM. Brief encounters of aggression and violence in primary care: a team approach to coping strategies. Fam Pract. 2002; 19: 504-10.

41 Miller WL, Crabtree BF. The dance of interpretation. In: Doing Qualitative Research (Crabtree BF, Miller WL eds.), 1999 Sage, Thousand Oaks, CA 127-43. 42 Graneheim UH, Lundman B. Qualitative content analysis in nursing research: concepts, procedures and measures to achieve trustworthiness. Nurs Educ Today. 2004; 24: 105-12.

43 Saldaña J. The Coding Manual for Qualitative Researchers. 2nd ed. 2012, London, UK: Sage Publications Ltd.

44 Whittemore R, Chase SK, Mandle CL. Validity in qualitative research. Qual Health Res. 2001; 11: 522-37.

45 Sandelowski M. Whatever happened to qualitative description? Res Nurs Health. 2000; 23: 334-40.

46 Lincoln Y, Guba E. Naturalistic Inquiry. 1985: Sage Publications, Inc.

47 Fishbein M. A reasoned action approach to health promotion. Med Decis Making. 2008; 28: 834-44.

48 Gerdtz MF, Daniel C, Dearie V, Prematunga R, Bamert M, Duxbury J. The outcome of a rapid training program on nurses' attitudes regarding the prevention of aggression in emergency departments: a multi-site evaluation. Int J Nurs Stud. 2013; 50: 1434-45.

49 Deans $C$. The effectiveness of a training program for emergency department nurses in managing violent situations. Aust J Adv Nurs. 2004; 21: 1722.

50 Grenyer B, Ilkiw-Lavalle 0, Biro P, Middleby-Clements J, Comninos A, Coleman M. Safer at work: development and evaluation of an aggression and violence minimization program. Aust Nz J Psychiat. 2004; 38: 804-10.

51 Nau J, Dassen T, Needham I, Halfens R. The development and testing of a training course in aggression for nursing students: a pre-and post-test study. Nurs Educ Today. 2009; 29: 196-207.

52 Zeller A, Needham I, Halfens R. Effekt einer Schulung in Aggressionsmanagement bei Schülerinnen und Schülern in der Pflegeausbildung 
(Effect of a training course in management of aggression and violence on nursing students). Pflege. 2006; 19: 251-8.

53 Nau J, Halfens R, Needham I, Dassen T. Student nurses' de-escalation of patient aggression: a pretest-posttest intervention study. Int J Nurs Stud. 2010; 47: 699-708.

54 Leary MR, Tate EB, Adams CE, Batts Allen A, Hancock J. Self-compassion and reactions to unpleasant self-relevant events: the implications of treating oneself kindly. Journal of personality and social psychology. 2007; 92: 887-904. 55 Neff K. Self-compassion: an alternative conceptualization of a healthy attitude toward oneself. Self and identity. 2003; 2: 85-101.

56 Lally P, Van Jaarsveld CH, Potts HW, Wardle J. How are habits formed: modelling habit formation in the real world. Eur J Soc Psychol. 2010; 40: 9981009.

57 Bowers L, Nijman H, Simpson A, Jones J. The relationship between leadership, teamworking, structure, burnout and attitude to patients on acute psychiatric wards. Soc Psychiatry Psychiatr Epidemiol. 2011 Feb; 46: 143-8. 58 Kislov R, Waterman H, Harvey G, Boaden R. Rethinking capacity building for knowledge mobilisation: developing multilevel capabilities in healthcare organisations. Implement Sci. 2014; 9: 166.

59 Leary M, Terry M, Batts AA, Tate E. The concept of ego threat in social and personality psychology: is ego threat a viable scientific construct? Pers Soc Psychol Rev. 2009; 13: 151-64.

60 Baker SE, Edwards R. How many qualitative interviews is enough? Expert voices and early career reflections on sampling and cases in qualitative research. 2012, Southampton, UK: National Centre for Resarch Methods; Economic \& Social Research Council.

61 Sturges JE, Hanrahan KJ. Comparing telephone and face-to-face qualitative interviewing: a research note. Qual Res. 2004; 4: 107-18.

62 Sullivan J. Skype: an appropriate method of data collection for qualitative interviews? The Hilltop Review. 2012; 6: 54 